\title{
Depth and space use of leopard coralgrouper Plectropomus leopardus using passive acoustic tracking
}

\author{
J. K. Matley ${ }^{1, *}$, M. R. Heupel ${ }^{1,2}$, C. A. Simpfendorfer ${ }^{1}$ \\ ${ }^{1}$ Centre for Sustainable Tropical Fisheries and Aquaculture \& College of Marine and Environmental Sciences, \\ James Cook University, Townsville, Queensland 4811, Australia \\ ${ }^{2}$ Australian Institute of Marine Science, PMB No. 3, Townsville, Queensland 4810, Australia
}

\begin{abstract}
Understanding fish movements can help define the seasonal importance of different habitats and isolate spatial and temporal vulnerability to exploitation. Leopard coralgrouper Plectropomus leopardus is one of the main targeted fishery species in the Great Barrier Reef; however, there is no information on long-term movement patterns based on continuous and frequent data points. The objective of this study was to determine long-term space use of $P$. leopardus and identify any seasonal variation in movement trends. A total of 124 P. leopardus were implanted with V13P acoustic transmitters between 2010 and 2012 and passively tracked. Forty-five VR2W receivers were deployed at 2 reefs to track the movements of tagged individuals. The influence of time of day, season, tagging year, location, and water temperature on several movement measures was investigated. Of the 124 fish tagged, 74 individuals had sufficient detections to be included in analysis of horizontal movement, and 55 were used to analyse vertical movements. Results showed increased horizontal movements and higher activity in deeper water during the day in the austral summer. Movement patterns, both vertically and horizontally, appeared to be influenced by water temperature, but also corresponded with spawning season. Despite increased movements during summer, individuals typically remained in a small area $\sim 0.5 \mathrm{~km}^{2}$ throughout detection periods, indicating that long-range spawning-related movements are rare and that adequate resources are obtained within a small section of habitat year-round. This study provides long-term $(\sim 3 \mathrm{yr})$ movement data for an economically significant reef fish and increases knowledge of spatial and temporal space use patterns.
\end{abstract}

KEY WORDS: Spawning $\cdot$ Foraging $\cdot$ Epinephelidae $\cdot$ Home range $\cdot$ Residency $\cdot$ Roaming Movement

\section{INTRODUCTION}

The extent and periodicity of movement by an animal within its environment provides a baseline indication of how biological demands are met. Space use patterns can identify temporal trends associated with obtaining resources (Jonsen et al. 2007) and provide spatial estimates of habitat selection (Knip et al. 2012). Knowledge of movement can also be used to delineate behavioural (Loseto et al. 2006, Heupel et al. 2012), ontogenetic (Knip et al. 2011), and physiological (Roscoe et al. 2010) adaptations. Understanding these biological traits is important when making informed management decisions for exploited species.

The methodological approaches used in the past to explore movement and space use of reef fish have included underwater visual census (UVC), markrecapture, and active acoustic tracking (see Zeller 
1997, Zeller \& Russ 1998 for descriptions). However, these methods are limited to fragmented and shortterm sampling with relatively small sample sizes. For example, UVC only covers a small area and may not represent reef-wide trends, observer presence may alter animal behaviour, and surveys are often depthlimited (Davies 1996, Thompson \& Mapstone 2002, Colton \& Swearer 2010, Miller et al. 2012). Markrecapture can yield low recapture rates (e.g. $<10 \%$, Grandcourt 2002, Sumpton et al. 2008) and short retention times of markings have been reported (e.g. Davies 1996, Samoilys 1997). Finally, active acoustic tracking requires intensive sampling and is limited to a small number of detections from multiple individuals or sparse individual detections (Tulevech \& Recksiek 1994, Szedlmayer 1997, Zeller 2002). A major limitation of previous approaches is that sightings, recaptures, or detections only represent a small proportion of time and typically cannot identify movement or behavioural patterns outside of monitoring or observation periods. Although a combination of techniques is typically preferred, passive acoustic tracking may be a useful alternative to the previously employed methods because tagged animals within range of receivers can be sampled simultaneously and long-term, independent of on-site effort (see Heupel \& Webber 2012 for review).

Concerns exist that fishery-targeted reef species, such as epinephelids, serranids, lethrinids, and lutjanids, are at risk of over-exploitation (Dulvy et al. 2004, Sadovy 2005, Newton et al. 2007). Many locations have already experienced drastic declines. For example in the Caribbean, the Nassau grouper Epinephelus striatus once contributed to $\sim 50 \%$ of total finfish landings but many populations are now considered commercially unviable due to over-exploitation of aggregations (Sadovy de Mitcheson \& Colin 2012). Knowing how reef species interact with their environment is valuable for delimiting individuals' spatial ranges and important habitats, which can improve management of large predatory fish. The leopard coralgrouper Plectropomus leopardus is a large (up to $\sim 60 \mathrm{~cm}$ total length) reef-associated predatory fish in the family Epinephelidae that has a broad distribution, and is the main target species in the Great Barrier Reef line fishery (Mapstone et al. 2008).

Past research using the methods described above has demonstrated that space use of $P$. leopardus varies largely between studies and sampling approaches: mark-recapture: home sites $\sim 2000 \mathrm{~m}^{2}, 300 \mathrm{~h}$ of SCUBA over 12 mo (Samoilys 1997); active acoustic tracking: home range $\sim 19000 \mathrm{~m}^{2}, 5$ sampling trips over 3 yr, each trip 1-3 mo (Zeller 1997); passive acoustic tracking: distance moved $\sim 10-15 \mathrm{~km} \mathrm{~d}^{-1}$, study area of $0.04 \mathrm{~km}^{2}$ sampled during $81 \mathrm{~d}$ (Bunt \& Kingsford 2014), but the majority of time is spent at a few locations within a small home range. Individuals are also reported to be more active during the day (Samoilys 1997, Zeller 1997, Connell \& Kingsford 1998), and move distances up to $\sim 5 \mathrm{~km}$ to spawn at specific aggregation sites (Zeller 1998). However, due to limitations of past research (described above), space use patterns of $P$. leopardus at different temporal scales (e.g. daily, monthly, yearly) require further investigation. Seasonal changes in activity and movement are of particular concern since this species aggregates in groups for spawning between October and December (Sadovy de Mitcheson \& Colin 2012, Carter et al. 2014). In fact, $>100$ reef-associated species are known to aggregate to spawn, many of which are large predatory fish that travel long distances to reach spawning sites (Sadovy de Mitcheson $\&$ Colin 2012). These species face increased risk of over-exploitation since aggregations can contain 1000s of individuals at predictable times and locations.

The goal of this study was to improve knowledge of how an exploited reef species, $P$. leopardus, behaves by identifying long-term space use patterns, such as home range, depth use, roaming, and residency using passive acoustic tracking. There is concern that fishing pressure (Little et al. 2005, Mclean et al. 2011) and environmental disturbances (Tobin et al. 2010) are detrimental to the sustainability of $P$. leopardus populations. Information on long-term distribution and movement will help define the effects human or environmental factors can have on population dynamics and demography, and assist in effective management of important fishery species.

\section{MATERIALS AND METHODS}

\section{Study area}

The study was located at Heron Island reef (HIR; $\left.23^{\circ} 26^{\prime} 31^{\prime \prime} \mathrm{S}, 151^{\circ} 54^{\prime} 50^{\prime \prime} \mathrm{E}\right)$ and One Tree Island reef (OTIR; $23^{\circ} 30^{\prime} 30^{\prime \prime} \mathrm{S}, 152^{\circ} 05^{\prime} 30^{\prime \prime} \mathrm{E}$ ) in the southern Great Barrier Reef, Queensland, Australia (Fig. 1). Both consist of fringing and patch coral reefs and a lagoonal area surrounding a small island. HIR is $\sim 10 \mathrm{~km}$ long and $5 \mathrm{~km}$ wide (reef area $\sim 35 \mathrm{~km}^{2}$ ) and OTIR is $\sim 5 \mathrm{~km}$ long and $3.5 \mathrm{~km}$ wide (reef area $\sim 16 \mathrm{~km}^{2}$ ). Depths are $<10 \mathrm{~m}$ in the lagoon at both reefs and reach $\sim 25 \mathrm{~m}$ along the reef slope. At low tide, the lagoon areas at both reefs are largely isolated. 


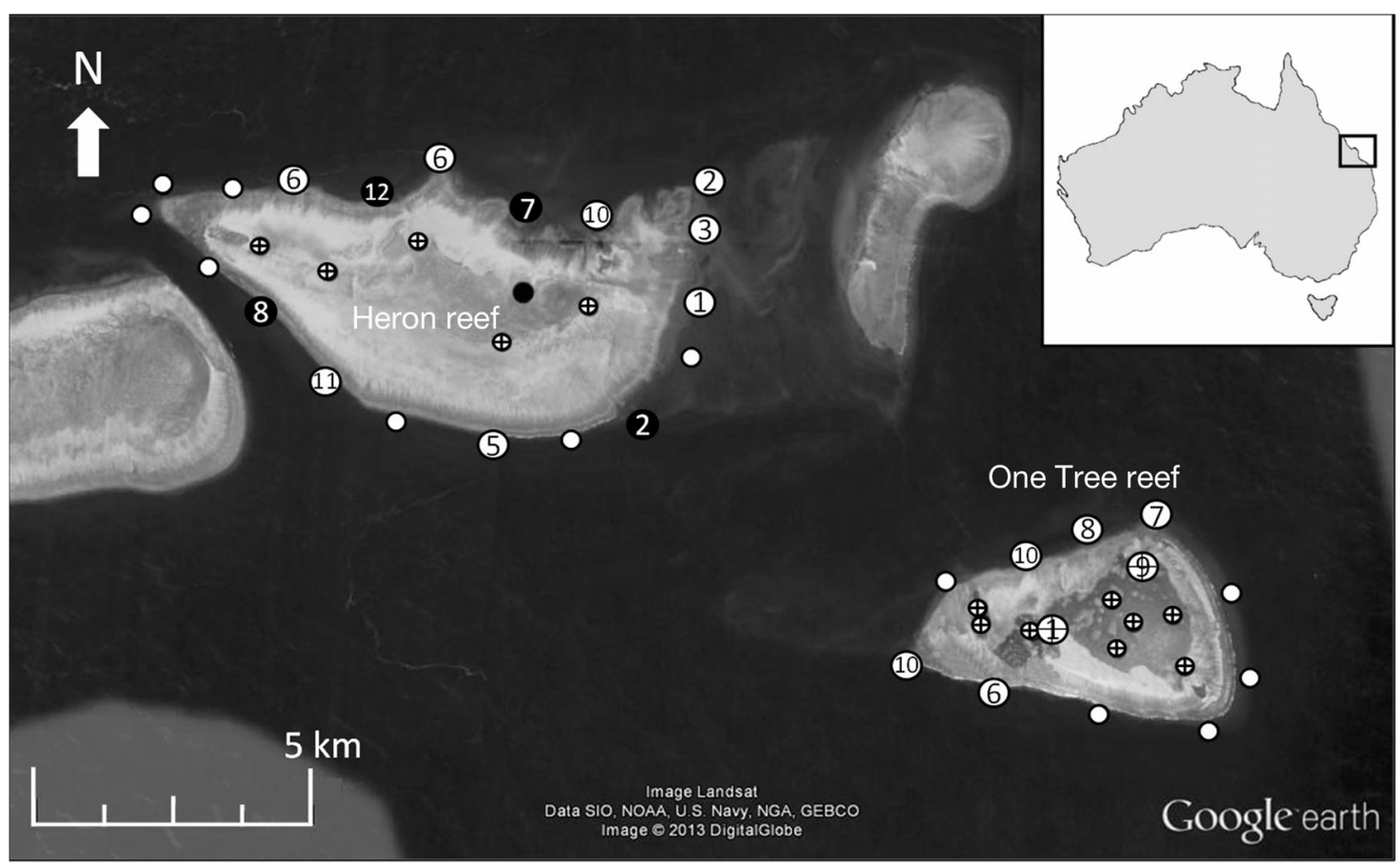

Fig. 1. Map of study area, with acoustic receiver locations outside $(O)$ and inside $(\oplus)$ the reef crest at Heron Island reef and One Tree Island reef. Black circles ( ) represent both receiver and sentinel tag location. The number of tagged coralgrouper Plectropomus leopardus $(\mathrm{n}=124)$ released near each receiver is shown as a number within the receiver location symbol

\section{Field methods}

Passive acoustic tracking was conducted at both reefs using VR2W receivers (Vemco). Forty-five receivers were deployed: 25 at HIR and 20 at OTIR (Fig. 1). Receivers were deployed $\sim 1 \mathrm{~m}$ above the seabed on long star pickets along the reef slope (10 to $22 \mathrm{~m}$ deep) and within reef lagoons (2 to $8 \mathrm{~m}$ deep) (Fig. 1). The detection range was tested at HIR by comparing the expected and observed number of detections from 5 transmitters moored at different depths and distances from receivers. Due to variability in environmental factors such as reef structure, detection ranges differed with depth and location, but on average the detection range was $\sim 300 \mathrm{~m}$ (M. R. Heupel unpubl. data). Acoustic receiver data were downloaded twice per year between August 2010 and February 2013. The final data used in this analysis was downloaded in February 2013. Based on detection range, acoustic receivers covered approx. $50 \%$ of the available habitat.

Individuals were captured using barbless hook and line, and released at the same location 20 to $940 \mathrm{~m}$ away from a receiver. Upon capture, the individual was immediately placed in an anaesthetic bath of Aqui- $S^{\circledast}(\sim 301)$ diluted with seawater (1:10 000). Prior to removing the hook, the swim bladder was vented to avoid barotrauma, if necessary. Once individuals lost equilibrium, they were measured $(\mathrm{mm}$ fork length), fitted with an external dart tag (PDS; Hall$\operatorname{print}^{\odot}$ ) in the dorsal musculature for identification, and moved to a fresh seawater bath where an acoustic transmitter was implanted using similar methods to Zeller (1999). A small incision $(\sim 2$ to $3 \mathrm{~cm})$ was made with a sterile scalpel blade in the ventral body wall and a V13P $(13 \times 36 \mathrm{~mm})$ acoustic transmitter (Vemco) with pressure sensor $( \pm 2.5 \mathrm{~m}$ manufacturer specified) was inserted into the body cavity. Each transmitter was programmed to randomly emit a unique coded signal (69 kHz) every 120 to $200 \mathrm{~s}$, with an expected battery life of $364 \mathrm{~d}$. The incision was closed using $2 / 0$ synthetic absorbable sutures and the individual was released after recovering from the anaesthetic ( 10 min procedure overall). Individuals were released in good condition in shallow regions to help avoid predation. A total of 124 Plectropomus leopardus were tagged between $\mathrm{Au}-$ gust 2010 and February 2012 (Table 1).

\section{Data analysis}

Transmitter data collected from receivers at HIR and OTIR were used to analyse patterns associated 
Table 1. Location, tagging year, sample size (n), and tagging date of coralgrouper Plectropomus leopardus released with acoustic transmitters

\begin{tabular}{|lccl|}
\hline Location & Tagging year & $\mathrm{n}$ & Date tagged \\
\hline Heron & 2010 & 14 & August 12-14 \\
& 2011 & 25 & March 15-26 \\
& 2011 & 2 & August 21 \\
& 2012 & 32 & February 8-15 \\
One Tree & 2010 & 10 & August 15-16 \\
& 2011 & 16 & March 31-April 15 \\
& 2012 & 25 & February 12-20 \\
Total & & 124 & \\
\hline
\end{tabular}

with frequency of detections, presence, and horizontal and vertical depth use. Detections from each transmitter were grouped in $2 \mathrm{~h}$ intervals to reduce correlation between consecutive data points. Initial analysis indicated grouping data into $2 \mathrm{~h}$ intervals accurately reflected fish behaviour while avoiding autocorrelation. To avoid spurious findings from transmitters with few detections (e.g. mortality events or movement outside detection range of receivers), individuals detected $<25$ times and/or for $<15 \mathrm{~d}$ were excluded from analyses. There were 3 main periods of transmitter deployment (August 2010, February-March 2011, February 2012). Since transmitters had a battery life up to $1 \mathrm{yr}$, detection data was available between August 2010 and February 2013. Due to the inconsistency in total months with data between years, individuals were divided into 3 groups based on the year tagging occurred (i.e. 2010, 2011, 2012). To determine if the distance of capture/release locations from a receiver affected the likelihood of an individual being included in analyses (i.e. $\geq 25$ detections and/or $\geq 15$ d), a generalized linear model (GLM) with binomial data was selected, where distance from receiver, locality on the reef (i.e. North, East, West, South, Lagoon), and reef were the explanatory variables (with an interaction term between locality and reef). These were tested against a response category of whether each individual met detection criteria or not (described above). Initially, the effect of fish size on movement patterns was analysed using simple linear regressions. However, it was not a significant predictor for any of the response variables and was not considered any further. All data analyses were completed in the $\mathrm{R}$ environment ( $\mathrm{R}$ Development Core Team 2013) and results were considered significant when $\mathrm{p}<0.05$. Mean values are presented with \pm standard error (SE) throughout.

\section{Detections}

The number of detections for each individual (after grouping in $2 \mathrm{~h}$ intervals) was grouped in $6 \mathrm{~h}$ bins as a percentage of total detections to allow for standardization among individuals. A repeated measures ANOVA (RM-ANOVA) determined the influence of time of day (00:00-06:00, 06:00-12:00, 12:00-18:00, 18:00-24:00 h), location (HIR, OTIR), and tagging year $(2010,2011,2012)$ on the frequency of detections (arcsine transformed) using the R packages 'car' (Fox \& Weisberg 2011) and 'nlme' (Pinheiro et al. 2013). Individual (i.e. transmitter number) was the within-subject factor and interactions among explanatory variables were identified. When significant, contrasts were fit to determine which categories differed from each other using the 'gmodels' package in $\mathrm{R}$ (Warnes 2013).

Receiver detections can be affected by environmental variables such as time of day (Payne et al. 2010). Therefore, sentinel tags (stationary transmitters moored near receivers) were deployed at depths between 2 and $15 \mathrm{~m}$ at the study site $(\mathrm{n}=5$; Fig. 1$)$ to identify fluctuations in receiver/detection efficacy. Analysis of each sentinel tag consistently showed more detections during daytime as opposed to night, possibly due to increased noise interference from nocturnal crustaceans (Heupel et al. 2006). Consequently, a standardising factor was applied to the number of detections in each time category to reduce diurnal detection disparities. The standardising factors were calculated by dividing the time category with the most detections by each subsequent time category for each sentinel tag. The mean categorical value from all sentinel tags (i.e. the standardising factor) was then multiplied by the number of detections for each respective time category for all transmitters. Following this, RM-ANOVAs were completed for standardised detection data as described above.

\section{Presence}

Trends relating to presence of $P$. leopardus within receiver arrays were investigated using residency and roaming indices. Monthly residency indices were calculated by dividing the number of days an individual was detected at any receiver by the number of days in each month. This measure estimated an individual's proclivity to remain near a receiver. Monthly roaming indices were calculated by dividing the number of receivers an individual was de- 
tected on each month by the total number of receivers in the array (i.e. HIR $n=25$; OTIR $n=20$ ). This index provided an estimate of movement patterns at a relatively large temporal scale. An RM-ANOVA (individual as repeated measure) was applied with season (January-March, April-June, July-September, October-December), location, and tagging year as explanatory variables, and residency and roaming indices as response variables (analysed separately). Interactions among explanatory variables were not analysed, and contrasts were fit when significant. Proportional data were arcsine transformed prior to analysis.

\section{Horizontal space use}

The locations of individuals were estimated using a mean position algorithm to provide centres of activity (COA) (Simpfendorfer et al. 2002). These locations represented the mean position of an individual based on the frequency of detections at receivers during the designated $2 \mathrm{~h}$ interval (Simpfendorfer et al. 2002). Space use was evaluated based on COAs using 95\% (home range extent) and $50 \%$ (core home range) utilization distributions (UDs) from Brownian bridge movement models (BBMMs). These models estimate space use based on the probability of an animal being in an area as determined by several factors such as start and end locations, the time between detections, and the speed of movement (Bullard 1999, Horne et al. 2007). The BBMM has advantages over other techniques (e.g. fixed kernels) because it incorporates uncertainties about the movement path by using ecologically based model parameters, such as animal mobility and location error (Powell 2000, Horne et al. 2007). The 'kernelbb' function in the $\mathrm{R}$ package 'adehabitatHR' (Calenge 2006) was used to estimate $95 \%$ and $50 \%$ UDs. Additionally, the 'liker' function was used to find the maximum likelihood estimation of animal mobility $\left(\sigma_{\mathrm{m}}^{2}\right)$ as described by Horne et al. (2007). A location error parameter $(\delta)$ of $200 \mathrm{~m}$ was used, based on a conservative estimate of receiver detection range. Additional $\mathrm{R}$ packages used include 'chron' (James \& Hornik 2013), 'maptools' (Bivand \& Lewin-Koh 2013), and 'PBSmapping' (Schnute et al. 2013).

Since movement was typically restricted to one or a few receivers (see results), 95\% and 50\% UDs were calculated for the entire detection period of each individual. If an individual was only detected on one receiver, a UD of $0.2 \mathrm{~km}^{2}$ was designated based on an estimated detection area around each receiver (i.e. area of a circle with $250 \mathrm{~m}$ radius). An ANOVA (Type III sums of squares) determined the effect of location and tagging year $(2010,2011,2012)$ on UDs $[\ln (x+1)]$ transformed; with each individual as a sample $n$ ). A post-hoc Tukey's test determined which tagging years or locations differed when they significantly influenced UDs.

\section{Vertical space use}

Since the depth range of individuals in this study was relatively small (typically $<20 \mathrm{~m}$ ), the $\pm 2.5 \mathrm{~m}$ accuracy of sensor data was evaluated to improve confidence identifying differences in depth use patterns. To do this, hourly tide height was subtracted from sensor depths of a transmitter that remained stationary on the sea floor near a receiver for a 2 mo period (i.e. a mortality event). This output provided an estimate of actual depth for $>16000$ detections where values only varied by $\pm 0.64 \mathrm{~m}$. Therefore, we consider this revised sensor error value to be more accurate for this study than the manufacturer-quoted error.

Depth was calculated by averaging values during each $2 \mathrm{~h}$ period. An RM-ANOVA was used to test for differences in depth use between time of day (00:0006:00, 06:00-12:00, 12:00-18:00, 18:00-24:00 h), season (January-March, April-June, July-September, October-December), location (HIR, OTIR) and tagging year $(2010,2011,2012)$, with individual as the within-subject factor. Additionally, to test for differences in variation of depth use (as opposed to depth itself) by individuals between time of day, season, location, and tagging year, an RM-ANOVA was completed using the standard deviation of mean depth for each individual (repeated measure) and affiliated season/time of day category. Contrasts were fit for both analyses when explanatory variables affected depth use. To explore the influence of water temperature on vertical space use, a linear mixed effects model was used with location, tagging year, and daily water temperature (Australian National Mooring Network-Integrated Marine Observing System, sensors from $\leq 20 \mathrm{~m}$ deep; www.imos.aodn.org.au) as candidate explanatory variables. The response variable was depth and individuals were treated as random factors. Due to the complexity and volume of data, interactions were not identified in the models. Candidate models were compared using Akaike information criterion with correction for small sample size $\left(\mathrm{AIC}_{\mathrm{C}}\right)$ from the 'nlme' package (Pinheiro et al. 2013) and model selection was done by averaging 
parameter estimates and predictions across models (model averaging) with the 'MuMln' package (Burnham \& Anderson 2002). The models with the lowest AIC values were considered to contain the most important factors influencing depth use.

Additionally, preliminary analysis revealed that a few individuals regularly moved to deeper water towards the end of the year. To further explore this novel depth use behaviour, raw detection data were plotted summarizing depth use of these individuals over time.

\section{RESULTS}

The GLM revealed that release distance of Plectropomus leopardus from a receiver did not affect whether an individual was included in further analyses. The locality on the reef was the only significant explanatory variable, explicitly the lagoon, where individuals were less likely to be detected after release $($ Estimate $=-2.752, \mathrm{SE}=1.320, z=-2.085, \mathrm{p}=$ $0.037)$.

\section{Detections}

After filtering out transmitters that were detected $<25$ times and/or for $<15 \mathrm{~d}, 74$ individuals were included in the analyses (Table 2). Of the 10 fish released in the lagoon at OTIR, 3 had sufficient detections to analyse. Two of these (\#6593 and \#6594) were only detected at the release location receiver, while \#6599 was only detected on one receiver outside the lagoon, north of the release location. No individual tagged outside the lagoon was detected inside of it. The mean detection period (i.e. time between first and last detection) for $P$. leopardus at HIR and OTIR was $286 \pm 10$ d (Table 2). During that period, the mean number of days that tagged animals were detected was $125 \pm 11$ (Table 2). Time of day had a significant effect on detections $\left(F_{3,204}=391.1\right.$, $\mathrm{p}<0.001)$, with a greater proportion of detections during the daytime (i.e. between 06:00 and 18:00) (Fig. 2a,b). Location $\left(F_{1,68}=0.035, \mathrm{p}=0.85\right)$ and tagging year $\left(F_{2,68}=0.004, \mathrm{p}=0.99\right)$ did not affect detections, although there was an interaction between time of day and location $\left(F_{3,204}=5.203, \mathrm{p}=0.02\right)$, with fewer detections between 12:00 and 18:00 at OTIR compared to HIR (Fig. 2a,b). Correcting for biased diurnal patterns in receiver efficacy produced the same findings as above (Fig. 2C,d).

\section{Presence}

Approximately $45 \%$ of individuals were detected on only one receiver, $33 \%$ at 2 receivers, $15 \%$ at 3 receivers, and $7 \%$ at $>3$ receivers. One individual (\#281) was detected on 15 receivers at both HIR and OTIR during a $191 \mathrm{~d}$ period (Fig. 3a). Survival of individuals detected at a single receiver was confirmed by examination of depth data which revealed variation in depth indicating vertical movement. Mean monthly roaming indices ranged between $0.04-0.07$ and 0.04-0.09 at HIR and OTIR, respectively, which is equivalent to being detected on $\sim 1.0-1.8$ receivers each month. Season $\left(F_{3,671}=10.18, \mathrm{p}<0.001\right)$ and tagging year $\left(F_{2,70}=4.40, \mathrm{p}=0.016\right)$ had an effect on roaming indices (Fig. 4). Contrasts revealed that roaming in October-December and January-March, were significantly greater than in April-June and July-September (Fig. 3b,c). Also, roaming of individuals tagged in 2010 was greater than in 2011 and 2012. Despite yearly differences in roaming indices, monthly trends among years were similar; particularly that roaming increased around October, and was lowest between April and September (Fig. 4).

Table 2. Mean \pm SE (range) values for the number of detections, detection period, days detected, and size of coralgrouper Plectropomus leopardus implanted with acoustic transmitters at Heron Island reef and One Tree Island reef between 2010 and 2012. The sample size (n) only includes transmitters with detections $\geq 25$ times and/or for $\geq 15 \mathrm{~d}$

\begin{tabular}{|lcrrrrr|}
\hline Location & Tagging year & $\mathrm{n}$ & \multicolumn{1}{c|}{ Fork length $(\mathrm{mm})$} & Detection period (d) & Days detected \\
\hline Heron & 2010 & 12 & $496.3 \pm 18.2(400-587)$ & $267.0 \pm 16.7(89-297)$ & $170.1 \pm 30.2(27-296)$ \\
& 2011 & 8 & $509 \pm 24.9(414-618)$ & $293.3 \pm 43.5(15-373)$ & $169.1 \pm 47.7(15-330)$ \\
\multirow{2}{*}{ One Tree } & 2012 & 25 & $507.4 \pm 13.2(391-627)$ & $294.7 \pm 17.0(54-370)$ & $118.4 \pm 15.8(22-362)$ \\
& 2010 & 4 & $542.75 \pm 10.1(521-564)$ & $208.0 \pm 33.6(134-296)$ & $116.0 \pm 60.1(46-296)$ \\
\multirow{2}{*}{ Total } & 2011 & 10 & $539.3 \pm 12.9(475-613)$ & $284.2 \pm 35.1(48-375)$ & $57.2 \pm 15.1(20-161)$ \\
& 2012 & 15 & $452.9 \pm 16.3(380-558)$ & $305.6 \pm 15.9(105-368)$ & $124.5 \pm 24.5(15-331)$ \\
& & 74 & $502.3 \pm 7.5(380-627)$ & $286.1 \pm 9.9(15-375)$ & $125.1 \pm 11.2(15-362)$ \\
\hline
\end{tabular}




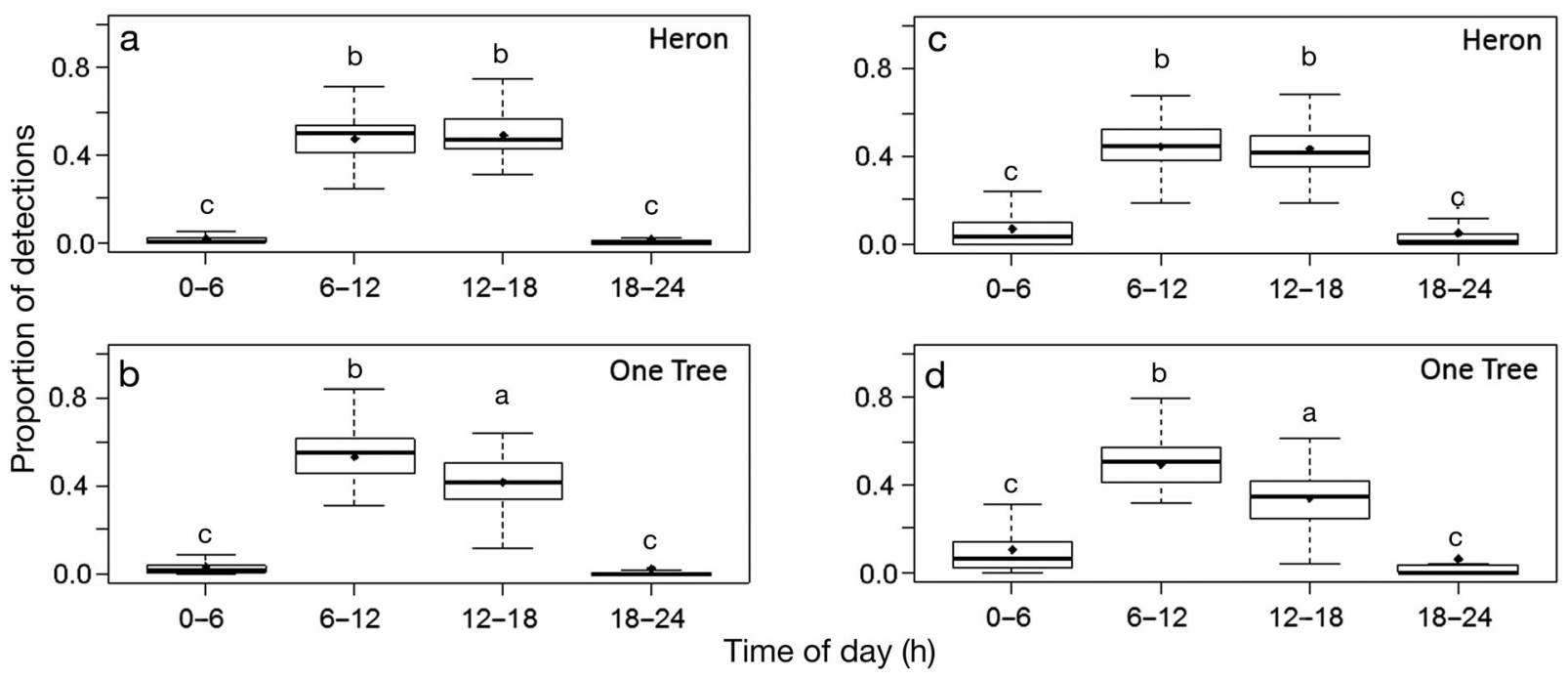

Fig. 2. Proportion of detections of coralgrouper Plectropomus leopardus at (a) Heron Island reef and (b) One Tree Island reef grouped into time categories. Proportional detections after correcting for fewer detections on sentinel tags at night are also plotted for (c) Heron Island reef and (d) One Tree Island reef. Boxes are 25th and 75th percentiles; whiskers represent 10th and 90th percentiles; the solid midline shows the median and the diamond, the mean. The letters above each plot represent statistically different time categories based on contrasts following the repeated measures ANOVA $(p<0.05)$
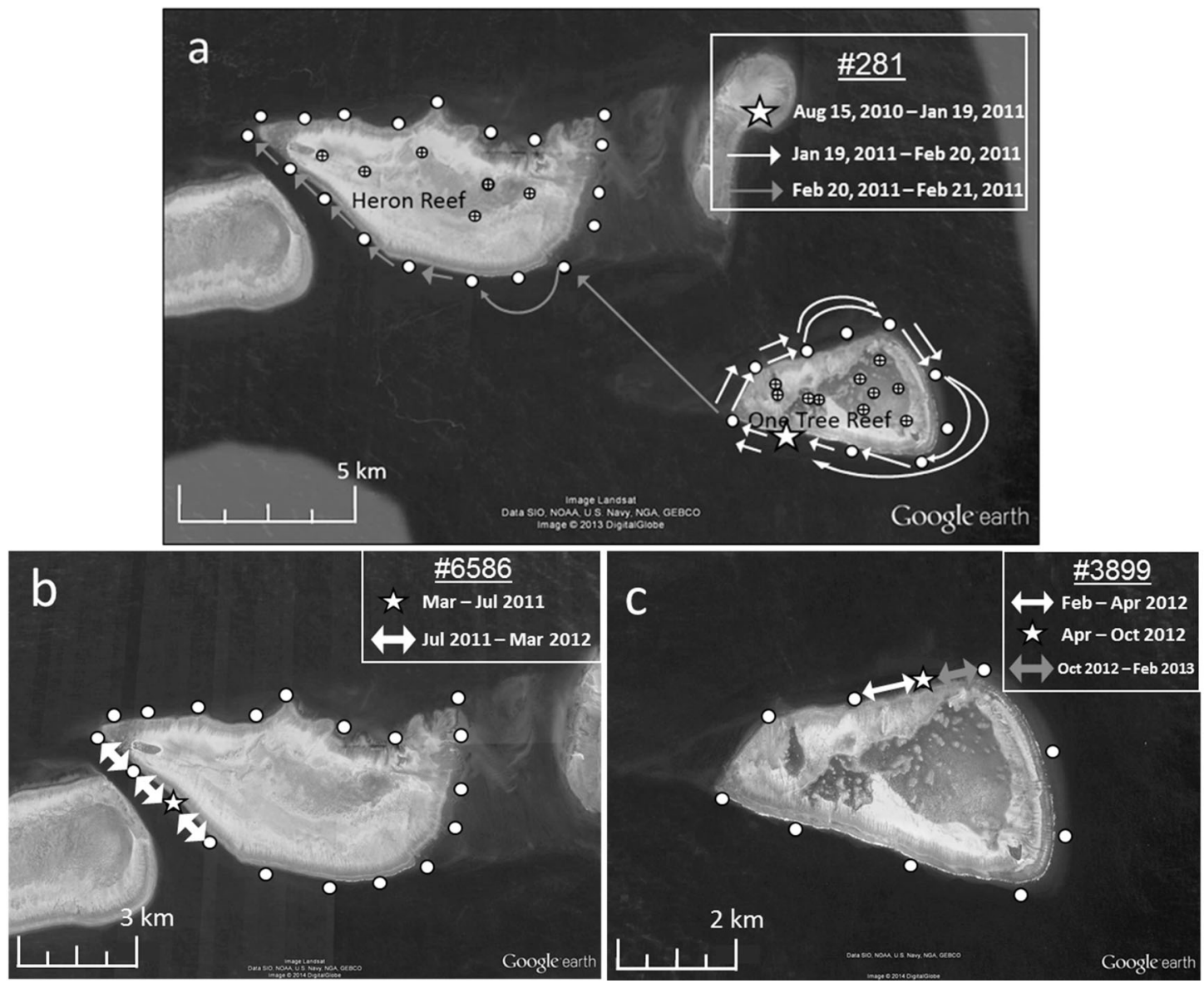

Fig. 3. Representation of coralgrouper Plectropomus leopardus movement (a) between Heron Island and One Tree Island reefs for ind. \#281, and examples of increased roaming during the Austral summer to adjacent receivers at Heron Island reef and One Tree Island reef by (b) ind. \#6586 and (c) ind. \#3899 

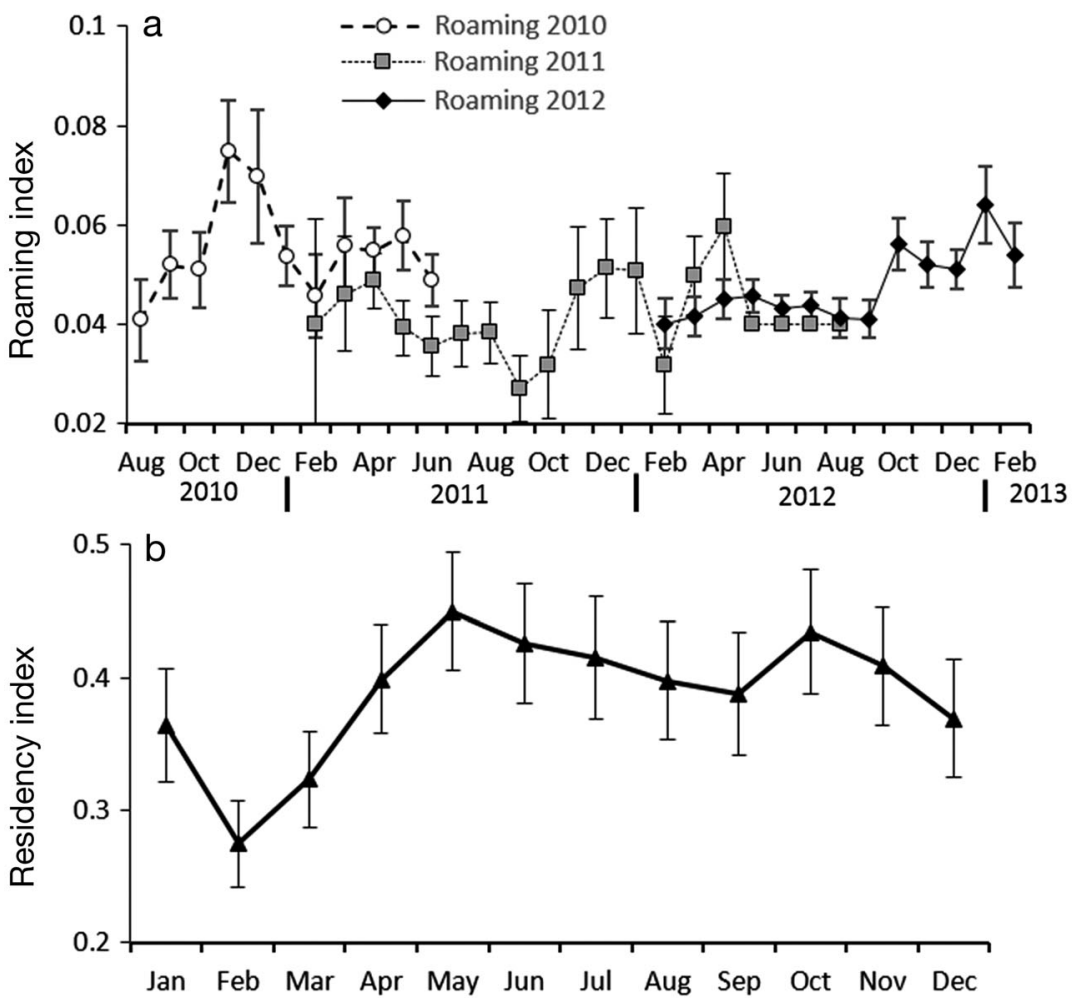

Fig. 4. Mean $( \pm$ SE) of (a) monthly roaming for tagging years in 2010, 2011, 2012 and (b) residency indices for coralgrouper Plectropomus leopardus at Heron Island reef and One Tree Island reef. Locations are grouped together since site did not impact roaming or residency values. Similarly, all tagging years are grouped for the residency output. Note: ind. \#281 was not included because the rare inter-reef movement inflated February values. Roaming in January-March and October-December was significantly greater $(p<0.05)$ than in April-June and July-September, and roaming of individuals tagged in 2010 was greater than in 2011 and 2012. Residency indices in January-March were lower than all other months

The mean residency index at both locations during the study was $0.41 \pm 0.03$, indicating that $P$. leopardus were within range of receivers nearly half the days in each month. The range of mean monthly residency indices was 0.36 to 0.49 at $\mathrm{HIR}$ and 0.25 to 0.48 at OTIR. Season $\left(F_{3,671}=\right.$ $11.65, \mathrm{p}<0.001$ ) was the only explanatory variable affecting residency of P. leopardus (Fig. 4); specifically, residency was significantly lower in January-March compared to the rest of the year.

\section{Horizontal space use}

Estimates of horizontal space use ranged between $0.20-28.18 \mathrm{~km}^{2}$ (95\% UD) and $0.13-3.99 \mathrm{~km}^{2}(50 \%$ UD) (Table 3). The mean size of space use at HIR and OTIR was $2.37 \pm$ $0.60 \mathrm{~km}^{2} \quad(95 \%$ UD) and $0.54 \quad \pm$ $0.08 \mathrm{~km}^{2}$ (50\% UD) (Table 3). The tagging year significantly influenced both $95 \%\left(F_{2,69}=3.38, \mathrm{p}=0.040\right)$ and $50 \%$ UDs $\left(F_{2,69}=3.24, \mathrm{p}=0.045\right)$, where UDs of individuals tagged in 2012 were smaller than those in 2010 $(p<0.05)$ (Table 3).

\section{Vertical space use}

A total of 55 individuals were analysed for vertical space use because depth sensors were only available on transmitters deployed in 2011 and 2012 (Table 4). Additionally, detection data from the 2 lagoon fish were omitted due to differences in depth/ habitat availability. The mean depth of these individuals was $9.66 \pm$ $0.03 \mathrm{~m}$ (Table 4$)$. Time of day $\left(F_{3,15504}\right.$ $=44.39, \mathrm{p}<0.001)$ and season $\left(F_{3,15504}=59.78, \mathrm{p}<0.001\right)$ had a significant effect on depth use. All time categories differed, but depth was greatest during the day, i.e. 06:00 to 18:00 h (Fig. 5a). Contrasts between seasons revealed that deeper water was frequented between October and December compared to other months (Fig. 5b). Season $\left(F_{3,121}=\right.$ $6.38, \mathrm{p}<0.001)$ and time of day $\left(F_{3,82}=3.85, \mathrm{p}=\right.$ $0.013)$ significantly influenced the standard deviation of depth use, and no interactions with location and tagging year existed. Contrasts between time of
Table 3. Mean \pm SE (range) $95 \%$ and $50 \%$ utilisation distributions (UDs) for coralgrouper Plectropomus leopardus using Brownian bridge movement models at Heron Island reef and One Tree Island reef. Significantly smaller 95\% and $50 \%$ UDs were detected in 2012 compared to 2010 ( $p<0.05$ ) as indicated by different lowercase letters beside each estimate

\begin{tabular}{|c|c|c|c|c|}
\hline Location & $\begin{array}{l}\text { Tagging } \\
\text { year }\end{array}$ & $\mathrm{n}$ & $95 \%$ UD $\left(\mathrm{km}^{2}\right)$ & $50 \%$ UD $\left(\mathrm{km}^{2}\right)$ \\
\hline Heron & $\begin{array}{l}2010 \\
2011 \\
2012\end{array}$ & $\begin{array}{c}12 \\
8 \\
25\end{array}$ & $\begin{array}{l}4.28 \pm 2.53(0.20-31.75)^{\mathrm{a}} \\
3.34 \pm 1.02(0.20-7.16)^{\mathrm{a}, \mathrm{b}} \\
1.46 \pm 0.38(0.20-8.94)^{\mathrm{b}}\end{array}$ & $\begin{array}{l}0.83 \pm 0.30(0.20-3.99)^{\mathrm{a}} \\
0.68 \pm 0.22(0.20-2.09)^{\mathrm{a}, \mathrm{b}} \\
0.41 \pm 0.06(0.13-1.06)^{\mathrm{b}}\end{array}$ \\
\hline One Tree & $\begin{array}{l}2010 \\
2011 \\
2012\end{array}$ & $\begin{array}{c}4 \\
10 \\
15\end{array}$ & $\begin{array}{l}8.36 \pm 6.65(0.20-28.18)^{\mathrm{a}} \\
1.71 \pm 1.24(0.20-12.56)^{\mathrm{a}, \mathrm{b}} \\
0.72 \pm 0.27(0.20-3.98)^{\mathrm{b}}\end{array}$ & $\begin{array}{l}0.85 \pm 0.56(0.20-2.66)^{\mathrm{a}} \\
0.60 \pm 0.28(0.20-2.91)^{\mathrm{a}, \mathrm{b}} \\
0.29 \pm 0.05(0.20-0.82)^{\mathrm{b}}\end{array}$ \\
\hline Total & & 74 & $2.37 \pm 0.60(0.20-28.18)$ & $0.54 \pm 0.08(0.13-3.99)$ \\
\hline
\end{tabular}


Table 4. Mean \pm SE (range) of depth values for coralgrouper Plectropomus leopardus tagged in 2011 and 2012 at Heron Island reef and One Tree Island reef

\begin{tabular}{|lccr|}
\hline Location & $\begin{array}{c}\text { Tagging } \\
\text { year }\end{array}$ & $\mathrm{n}$ & Depth $(\mathrm{m})$ \\
\hline Heron & 2011 & 8 & $9.10 \pm 0.05(1.10-20.35)$ \\
& 2012 & 25 & $11.76 \pm 0.06(0.01-21.98)$ \\
One Tree & 2011 & 9 & $7.47 \pm 0.07(2.64-19.12)$ \\
& 2012 & 13 & $8.57 \pm 0.04(0.20-21.43)$ \\
Total & & 55 & $9.66 \pm 0.03(0.01-21.98)$ \\
\hline
\end{tabular}

day revealed there was more variation in depth use during daytime as opposed to night (Fig. 6a). Greater variation in depth use also existed in October-December compared to other months (Fig. 6b). The effect of location, tagging year, and water temperature on $P$. leopardus depth use from several
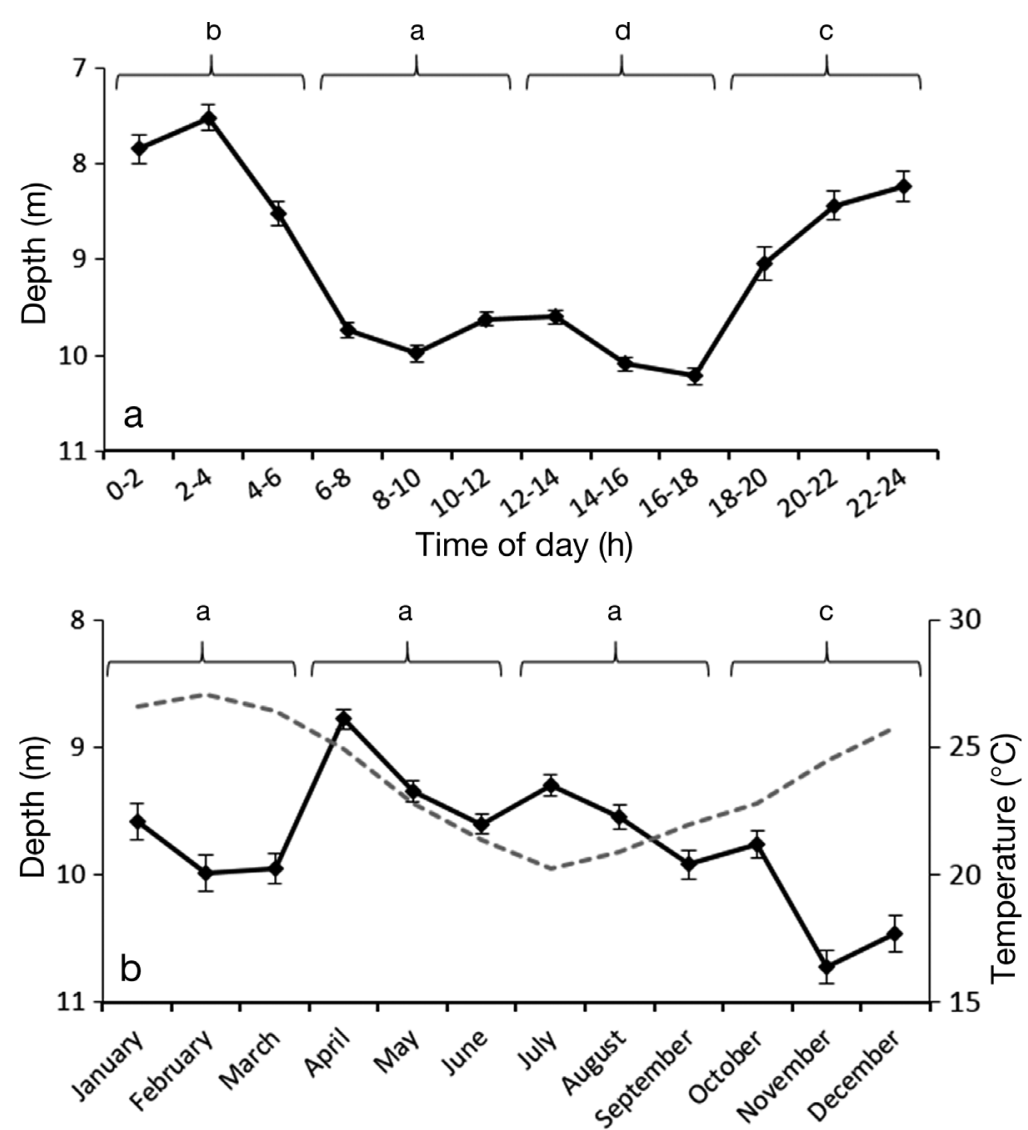

Fig. 5. Depth use (mean $\pm \mathrm{SE}$ ) of coralgrouper Plectropomus leopardus grouped by (a) time of day and (b) month for all tagging years $(2010,2011$, 2012) and locations (Heron Island reef and One Tree Island reef). The dashed line in (b) shows mean water temperature. The letters above each series represent statistically different time (00:00-06:00, 06:00-12:00, 12:00-18:00, 18:00-24:00 h) and month (January-March, April-June, July-September, October-December) categories based on contrasts following the repeated measures ANOVA $(p<0.05)$ candidate models showed that water temperature was the most important factor (Table 5; Estimate $=$ $0.015, \mathrm{SE}=0.005, z=3.256, \mathrm{p}=0.001$ ).

Two individuals (\#6552 detected at 2 adjacent receivers in the northwest of HIR and \#6580 detected at one receiver in the southwest of OTIR) demonstrated unique swimming patterns between October and January, where both used deeper water around the new moon (Fig. 7a,b). At a finer scale, these individuals (particularly \#6580) demonstrated diurnal activity, swimming to deeper water primarily during the latter half of the day (Fig. $7 \mathrm{c}, \mathrm{d}$ ).

\section{DISCUSSION}

It is crucial to understand the movement patterns of exploited species to ensure management measures encompass the resource use of targeted species. Short-term data cannot indicate whether individuals shift home range areas over time or whether specific habitats are used during key times. Thus, long-term data, such as that provided by acoustic monitoring in this study, are the only means of identifying seasonal or annual patterns in behaviour and movement at scales relevant to management. The results of this study showed that Plectropomus leopardus moved more and used deeper water during the day in the Austral summer. Seasonal differences in space use were related to water temperature and corresponded with spawning periods. Despite these seasonal changes, individual $P$. leopardus remained in relatively small areas $\left(\sim 0.5 \mathrm{~km}^{2}\right)$ throughout the year with no evidence of long-range movement to aggregate for spawning. These results indicate that localised movements on the reef provide sufficient access to food, shelter, and mates. Lack of evidence for spawningrelated migrations in this region suggests protection of spawning aggregations may not be feasible for this population.

Detection differences between day and night indicated that $P$. leopardus were more active on the reef during daytime. At night, they were likely 

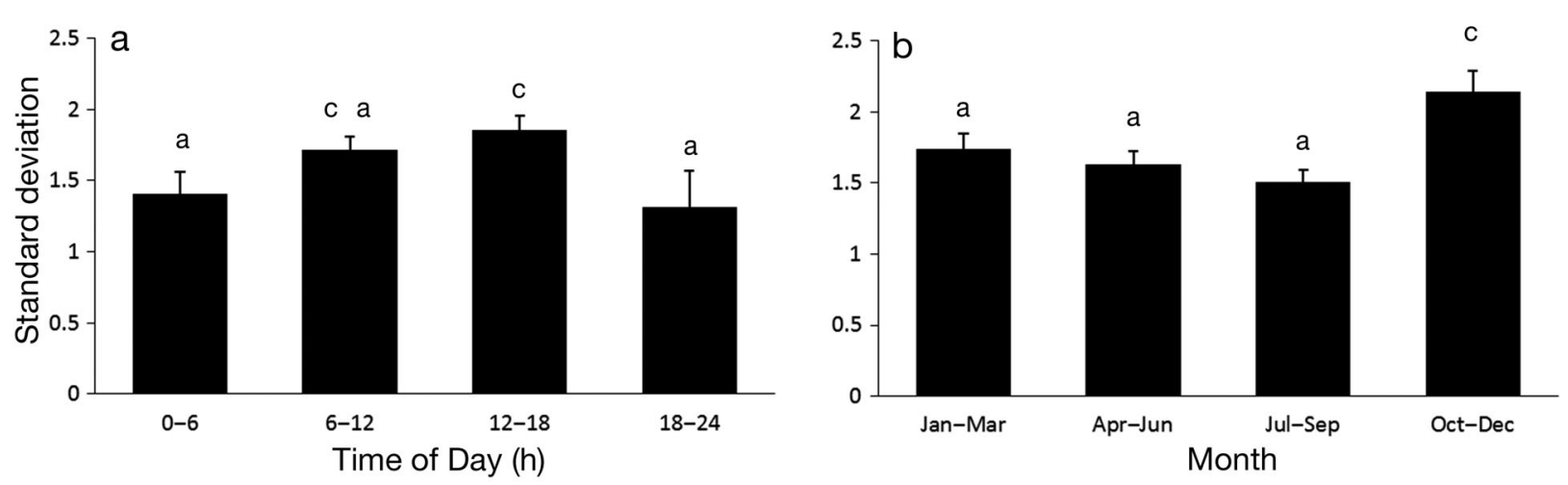

Fig. 6. Mean $( \pm \mathrm{SE})$ of standard deviation of recorded depth for the coralgrouper Plectropomus leopardus grouped by (a) time of day and (b) month for all tagging years $(2010,2011,2012)$ and locations (Heron Island reef and One Tree Island reef). The letters above each plot represent statistically different time (00:00-06:00, 06:00-12:00, 12:00-18:00, 18:00-24:00 h) and month (January-March, April-June, July-September, October-December) categories based on contrasts following repeated measures ANOVA $(\mathrm{p}<0.05)$

refuging within shelter sites (e.g. large corals, overhangs, tunnels, and reef edges) for protection (Samoilys 1997, Zeller 1997), resulting in weakened acoustic signal transmission (Hutchinson \& Rhodes 2010). Despite accounting for detection differences from sentinel tags, nightly detections were still less frequent than during the day. Reduced activity at night was also demonstrated by Zeller (1997), who found that on $88 \%$ of monitored nights, individuals $(\mathrm{n}=6)$ remained in the same location. Refuging within reef structure is a common predator avoidance strategy employed by species that rest at night, with some parrotfishes going as far as surrounding themselves in a mucous bubble to reduce odour trails (Winn \& Bardach 1959, Dubin \& Baker 1982). Therefore, limited movement and refuging within reef structures is likely a successful survival strategy for $P$. leopardus.

The proportion of detections at HIR was similar between morning (06:00 to 12:00 h) and afternoon (12:00 to $18: 00 \mathrm{~h})$, suggesting that individuals were active throughout the day at this location, although specific behaviours during these periods could not be
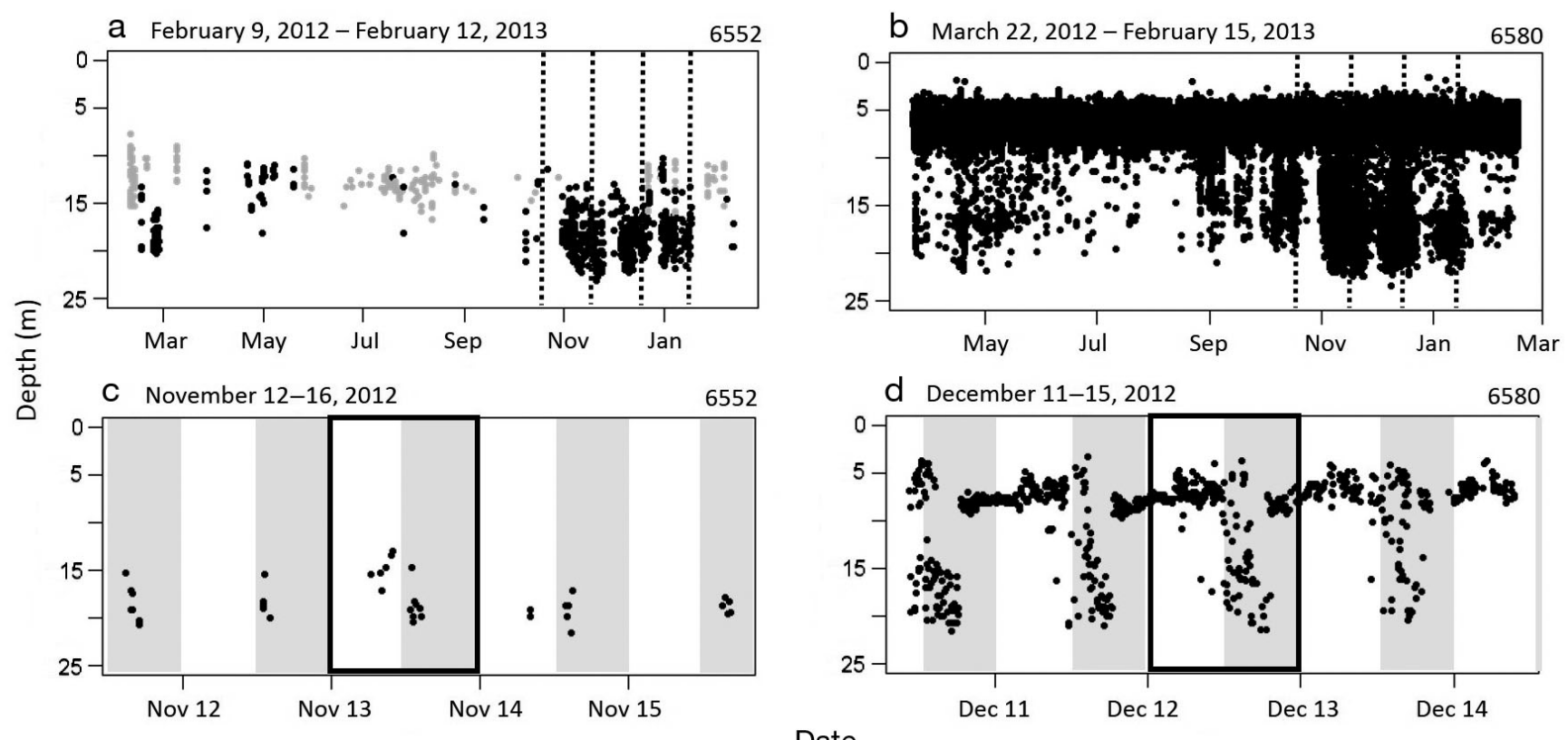

Date

Fig. 7. Total detections from 2 coralgrouper Plectropomus leopardus: ind. \#6552 (Heron Island reef) and ind. \#6580 (One Tree Island reef) at a scale $(\mathrm{a}, \mathrm{b})$ of $\sim 1 \mathrm{yr}$, and $(\mathrm{c}, \mathrm{d}) 5 \mathrm{~d}$ during spawning season. Black dotted lines $(\mathrm{a}, \mathrm{b})$ and black boxes (c,d) indicate the new moon. Grey and black dots in (a) signify the 2 different respective receivers that detected ind. \#6552, and shaded areas in $(c, d)$ represent noon to midnight 
Table 5. Model selection examining the effect of location, tagging year, and daily water temperature on coralgrouper Plectropomus leopardus $(\mathrm{n}=55)$ depth use, using corrected Akaike information criterion $\left(\mathrm{AIC}_{\mathrm{c}}\right)$ accounting for small sample size. The best 4 models (i.e. lowest $\mathrm{AIC}_{\mathrm{C}}$ ) and the null model are presented using model averaging as well as the relative importance of each model (i.e. weight)

\begin{tabular}{|c|c|c|c|c|}
\hline Model & df & $\mathrm{AIC}_{\mathrm{c}}$ & $\Delta \mathrm{AIC}$ & Weight \\
\hline M1 Depth Temperature & 4 & 64796.2 & 0 & 0.46 \\
\hline M2 Depth Location + Temperature & 5 & 64797.7 & 1.46 & 0.22 \\
\hline M3 Depth Tagging Year + Temperature & 5 & 64797.7 & 1.53 & 0.21 \\
\hline M4 Depth Location + Tagging Year + Temperature & 6 & 64799.3 & 3.14 & 0.10 \\
\hline M5 Depth 1 (null model) & 3 & 64805.9 & 9.66 & 0 \\
\hline
\end{tabular}

possible reasons why water temperature and/or season would affect movement. First, physiological and biochemical benefits of warmer temperatures (e.g. increased swimming ability; Claireaux et al. 2006) may facilitate greater activity during the Austral summer. Second, increased movement during Austral summer may be related to foraging. Kingsford (1992) found that $P$.

determined. Similarly, the number of locations used by $P$. leopardus did not differ at Lizard Island during the day (Zeller 1997), nor did abundance counts vary at OTIR from 1991 to 1993 when divided into $2 \mathrm{~h}$ categories (05:00-07:00; 11:00-13:00; 17:00-19:00 h) (Connell \& Kingsford 1998). In this study, OTIR had fewer detections in the afternoon compared to morning, yet afternoon still accounted for $\sim 40 \%$ of detections. Whether the difference between locations was due to fish behaviour or physical/environmental factors is difficult to assess. Nevertheless, Bunt \& Kingsford (2014) suggested visually oriented foraging activity was responsible for greater mean daily movements during morning (05:00 to 10:00 h) in the lagoon at OTIR.

Site fidelity was relatively high for individuals at both HIR and OTIR. Almost half of individuals were only detected on one receiver; otherwise detections occurred mainly on adjacent receivers. Additionally, daily detections were common throughout monitoring periods. High site fidelity has been shown in P. leopardus (e.g. Zeller 1997, Bunt \& Kingsford 2014), but not to the temporal scale in this study (i.e. mean detection period $\sim 285 \mathrm{~d} \mathrm{yr}^{-1}$ over $3 \mathrm{yr}$ ). Other studies have also demonstrated high site fidelity of epinephelids such as squaretail coralgrouper $P$. areolatus (Hutchinson \& Rhodes 2010), dusky grouper Epinephelus marginatus (Pastor et al. 2009), gag grouper Mycteroperca microlepis (Kiel 2004), and goliath grouper E. itajara (Frias-Torres 2006). Results presented here indicate that home sites of $P$. leopardus are consistently maintained over periods extending up to a year. The consistency of site attachment and space use across individuals and reefs suggest this is a widespread pattern of habitat use within this species.

Both roaming and residency indices indicated that individuals were more transient between October and March. Increased movements away from receivers during the Austral summer were probably related to water temperature. There are several leopardus at OTIR consumed mostly pelagic fishes (e.g. Clupeidae and Engraulidae) during summer and demersal fishes during winter (e.g. Apogonidae). Interestingly, P. leopardus frequently follow schools of pelagic planktivores when they are abundant (Goeden 1978, Samoilys 1987). Therefore, increased movement during summer may be related to the seasonal variation in prey availability and selection. Finally, seasonal differences relating to presence near receivers may have been related to reproductive behaviour. Many large groupers move long distances during spawning periods, particularly for site-specific aggregative reproductive activity (Sadovy de Mitcheson \& Colin 2012). However, the relatively complex and flexible reproductive dynamics of $P$. leopardus result in a combination of strategies (e.g. transient aggregator, resident aggregator, and resident nonaggregator; Sadovy de Mitcheson \& Colin 2012). For example, Zeller (1998) actively tracked 13 individuals moving 220 to $5210 \mathrm{~m}$ to reach spawning aggregation sites; yet this only accounted for $31 \%$ of fish tagged. These results indicated that almost $70 \%$ of tracked individuals either failed to undertake spawning behaviours or spawned near their site of capture. In this study, increased movement occurred, at least in part, during the $P$. leopardus spawning season at Heron Island (Carter et al. 2014). Therefore, increased roaming during summer may have occurred while searching for partners for spawning or due to increased feeding activity associated with spawning (Samoilys \& Squire 1994, Davies 1996). The small range of both roaming and residency indices, and small changes in space use, suggest that transient spawning (or spawning-independent) movements are rare for this portion of the $P$. leopardus population. Similarly, $P$. areolatus inhabit relatively small areas $(0.004$ to $0.12 \mathrm{~km}^{2}$ ) throughout both reproductive and non-reproductive periods in Micronesia, and many individuals reside within close range of spawning aggregation sites (Hutchinson \& Rhodes 2010). 
Brownian bridge UDs revealed that $P$. leopardus were mainly restricted to small areas. The extent of movement (i.e. $95 \%$ UD) was usually $<2.5 \mathrm{~km}^{2}$, while core use area (i.e. $50 \%$ UD) was $\sim 0.5 \mathrm{~km}^{2}$. The individuals tagged in 2010 had higher UDs (and roaming indices) than those tagged in 2011 and 2012. Further investigation into environmental influences is needed to address this finding. However, the different tagging dates (August 2010, February-March 2011, February 2012) could have biased results since detection periods for individuals tagged in 2010 commenced later in the year than individuals tagged in 2011 and 2012. Estimates of P. leopardus space use have varied in past studies. For example Samoilys (1997) found that $59 \%(n=101)$ of branded fish (markrecapture) remained in the same area $\left(\sim 2000 \mathrm{~m}^{2}\right) 4$ to 5 mo after release. Meanwhile, active acoustic tracking revealed home ranges between 10000 and $19000 \mathrm{~m}^{2}$ (Zeller 1997) when tracked for $\sim 3$ mo. The analytical approach to estimate space use from these studies consisted of calculating the area of convex polygons encompassing recapture (or redetection) sites. This method can be highly influenced by outlying detection points and increasing sample size tends to increase biases associated with area estimates (Burgman \& Fox 2003). The use of a continuous-time stochastic model of movement was selected in this study because estimates are calculated based on maximum likelihood parameters and incorporate several influential factors (e.g. time between detections and speed of movement). Overall, home range estimates for $P$. leopardus were larger than other studies, and were representative of longer periods and covered a larger sampling area. Greater spatial resolution for individual movement, and identification of more specific behaviour-based activities would require a denser receiver array (e.g. Vemco Positioning System; Espinoza et al. 2011, Bunt \& Kingsford 2014). Nevertheless, home range estimates were comparable to other reef species with high site fidelity. For example, Currey et al. (2014) estimated that horizontal space use of redthroat emperor Lethrinus miniatus at HIR was $0.36 \mathrm{~km}^{2}$ (50\% UD) and $1.93 \mathrm{~km}^{2}$ (95\% UD). Additionally, in a coastal Kenyan marine park, greasy grouper Epinephelus tauvina demonstrated stable site attachment with home ranges between 0.07 and $0.73 \mathrm{~km}^{2}$ (KaundaArara \& Rose 2004).

Although most $P$. leopardus remained within a small area throughout the study, some moved long distances around the reef they were released at; one individual (\#281) travelled from OTIR to HIR after 6 mo residency at OTIR. Fish size had no influence on movements or space use in this study, a finding that parallels other studies (e.g. Zeller 1997, Bunt \& Kingsford 2014). The effect of sex was not explored because internal identification of gonads was not attempted during surgery, but is not likely contributory since some of the long-distance movements occurred outside the spawning season (see also Zeller 1997, 1998). Also, site attachment was apparent before and after long movements, making predation events (e.g. eaten by a shark) an unlikely explanation for these movements. The reason some individuals moved far is probably related to intra-specific variability common in reef fish movements, where some individuals are migratory and others are resident (Chapman et al. 2012). For example, using the same acoustic receiver array as this study, Currey et al. (2014) tracked 26 L. miniatus at HIR and found that half were resident (detected on only one receiver) and the other half used an area $\sim 4 \mathrm{~km}^{2}$, while 1 individual moved $\sim 160 \mathrm{~km}$ to the Swain reefs. Considering the temporal extent of acoustic tracking and that most individuals $(>75 \%)$ were detected at $\leq 2$ receivers, long-range movements of $P$. leopardus in this region appear to be uncommon.

It should be noted however that movements outside detection ranges could have occurred and as such these data may underestimate movements away from the study reefs. Individuals detected for short periods or not at all may have moved to adjacent reefs, maintained home ranges outside the range of the acoustic array, or suffered mortality. Due to the inability to determine the actual fate and behaviour of these individuals they were excluded from analyses. Interestingly, release distance (from a receiver) did not affect the number of detections, indicating that tagging was suitable for fish caught $<1 \mathrm{~km}$ from a receiver. The reason why the lagoon at OTIR was the least likely location to obtain adequate detections is unclear, but may be related to individuals moving outside the lagoon (e.g. \#6599) when the tide permitted or due to receiver placement. Overall, movement between the outer reef edge and the lagoon at HIR and OTIR was rare in this study, since all $P$. leopardus detected in the lagoon were tagged there and only \#6599 was detected moving outside of it.

Acoustic transmitters equipped with pressure sensors provided high-resolution long-term depth measurements for $P$. leopardus. The mean depth used was $\sim 10 \mathrm{~m}$, typically ranging between 3 and $18 \mathrm{~m}$. Deeper water was used during the day compared to night likely in relation to diurnal activity patterns, such as foraging or conspecific interactions along the reef edge and slope (St. John 2001, Kingsford 2009). Sim- 
ilar diurnal depth use patterns were detected in the ocean whitefish Caulolatilus princeps where deeper sand habitats optimised foraging during the day and shallower rocky reef and kelp habitats provided refuge at night (Bellquist et al. 2008). However, it is unclear why individuals would not simply refuge at similar or the same depths used during the day. Presumably there is some advantage to refuging in shallower water, perhaps due to increased shelter locations, better predator avoidance, or behavioural thermoregulation (see below). Bunt \& Kingsford (2014) examined spawning-related aggregative movements of individuals in a lagoon at OTIR between 2001 and 2002 and found a similar pattern during the non-reproductive period (January and February), but the opposite trend occurred during the reproductive period in November and December (i.e. P. leopardus were deeper at night). The present study encompassed a larger area, and may not be comparable to the shallow $(<7.5 \mathrm{~m}$ ) lagoon environment sampled by Bunt \& Kingsford (2014).

Some $P$. leopardus exhibited a small range of depths throughout detection periods, while for others, monthly mean depths varied considerably (>5 m). Consequently, differences in the variation in depth use were explored in addition to actual depth differences. Similar to depth patterns, there was more variation in depth use during daytime and between October and December (reproductive season), which also corresponded to greater depth use when water temperature was warmer. Reduced activity at night for refuging (Zeller 1998, Bunt \& Kingsford 2014) explains why individuals moved less in the water column between 18:00 and 06:00 h. Deep movements to cooler waters could have been related to behavioural thermoregulation to minimize metabolic costs associated with feeding/digestion (e.g. Bevelhimer \& Adams 1993) or aerobic scope (e.g. Nilsson et al. 2009). Interestingly, a few individuals made marked daily deep movements (up to $25 \mathrm{~m}$ ) near home sites that overlapped with spawning periods. These deep dives mainly occurred during new moon periods, in the afternoon/at dusk between October and January, all of which are within the main periods of $P$. leopardus courtship and spawning activity (Samoilys \& Squire 1994, Ferreira 1995, Samoilys 1997, Zeller 1998). Interpretation of the observed deep movements is that individuals used deeper parts of reefs to participate in spawning-related behaviour (e.g. courtship, spawning, or recovery). For example, Zeller (1998) found that $P$. leopardus displayed peak spawning activities during new moon periods in the Austral summer at Lizard Island and identified 4 spawning sites, all of which were situated on the lower reef slope between 15 and $20 \mathrm{~m}$.

Passive acoustic tracking provided long-term ( $3 \mathrm{yr})$, medium-scale movement data surpassing approaches employed previously to monitor $P$. leopardus movement. The data presented here are representative of behavioural patterns independent of aggregative spawning - an occurrence that may not be commonplace for this species (Samoilys 2000, Tobin et al. 2013). Space use and movement patterns have direct relevance to current issues threatening sustainability of reef fish including vulnerability to fishing during spawning season (Sadovy de Mitcheson \& Colin 2012, Tobin et al. 2013), Marine Protected Area delineation (Monaco et al. 2007, Bunt \& Kingsford 2014), effects of severe weather/climate change (Nilsson et al. 2009, Tobin et al. 2010), and determining 'spillover' between reefs/management zones (McClanahan \& Mangi 2000, Zeller et al. 2003). For large marine predators with high site fidelity, it is recommended that management strategies are geared to localised scales (e.g. Pastor et al. 2009) such as maximising habitat availability or establishing marine reserves for populations regardless of season. Nevertheless, persistent spawning aggregation sites should be protected during spawning season as they can attract numerous individuals from large catchment areas (Sadovy de Mitcheson \& Colin 2012). Moreover, physiological and behavioural responses to environmental changes need to be closely monitored because future changes in temperature may adversely influence populations of reef fish (e.g. Munday et al. 2008, Donelson et al. 2011). Improved understanding of daily and seasonal spatial patterns throughout and between years is necessary for managers and policy makers to help balance the economic and conservation demands of reef fisheries.

Acknowledgements. This research was conducted under research permits from the Great Barrier Reef Marine Park Authority (G10/33754.1 and G10/33758.1) and Queensland Department of Primary Industries and Fisheries permit number 144482. Funding was provided as part of a Future Fellowship (\#FT100101004) to M.R.H. from the Australian Research Council; additional funding was provided by the Australian Institute of Marine Science (AIMS). Additional research funding was granted to J.K.M. from James Cook University School of Earth and Environmental Sciences. All research was conducted under James Cook University (JCU) Animal Ethics Permit A1566. Acoustic receivers utilised in this research are part of the Australian Animal Tagging and Monitoring (AATAMS) Facility of the Integrated Marine Observing System. The authors thank AATAMS staff for their assistance in downloading and maintaining acoustic receivers. The authors also thank 
AIMS and JCU staff and students who helped with field efforts and analysis including: A. Tobin, F. de Faria, S. Moore, L. Currey, V. Udyawer, M. Espinoza, E. Ledee, D. Abdo and D. Knip. We thank 3 anonymous reviewers for their comments which have greatly improved this text.

\section{LITERATURE CITED}

Bellquist LF, Lowe CG, Caselle JE (2008) Fine-scale movement patterns, site fidelity, and habitat selection of ocean whitefish (Caulolatilus princeps). Fish Res 91:325-335

> Bevelhimer MS, Adams SM (1993) A bioenergetics analysis of diel vertical migration by Kokanee salmon, Oncorhynchus nerka. Can J Fish Aquat Sci 50:2336-2349

Bivand R, Lewin-Koh N (2013) maptools: tools for reading and handling spatial objects. R package v. 0.8-27. http: //CRAN.R-project.org/package=maptools

Bullard F (1999) Estimating the home range of an animal: a Brownian bridge approach. MSc thesis. University of North Carolina, Chapel Hill, NC

> Bunt C, Kingsford MJ (2014) Movement, habitat utilization and behaviour of coral trout Plectropomus leopardus during and after the reproductive period on the southern Great Barrier Reef. Mar Ecol Prog Ser 496:33-45

Burgman MA, Fox JC (2003) Bias in species range estimates from minimum convex polygons: implications for conservation and options for improved planning. Anim Conserv 6:19-28

Burnham KP, Anderson DR (2002) Model selection and multimodel inference: a practical information-theoretic approach. Springer-Verlag, New York, NY

> Calenge C (2006) The package adehabitat for the R software: a tool for the analysis of space and habitat use by animals. Ecol Model 197:516-519

> Carter AB, Russ GR, Tobin AJ, Williams AJ, Davies CR, Mapstone BD (2014) Spatial variation in the effects of size and age on reproductive dynamics of common coral trout Plectropomus leopardus. J Fish Biol 84:1074-1098

> Chapman BB, Skov C, Hulthén K, Brodersen J, Nilsson PA, Hansson L, Brönmark C (2012) Partial migration in fishes: definitions, methodologies and taxonomic distribution. J Fish Biol 81:479-499

Claireaux G, Couturier C, Groison AL (2006) Effect of temperature on maximum swimming speed and cost of transport in juvenile European sea bass (Dicentrarchus labrax). J Exp Biol 209:3420-3428

> Colton M, Swearer S (2010) A comparison of two survey methods: differences between underwater visual census and baited remote underwater video. Mar Ecol Prog Ser 400:19-36

Connell SD, Kingsford MJ (1998) Spatial, temporal and habitat-related variation in the abundance of large predatory fish at One Tree Reef, Australia. Coral Reefs $17: 49-57$

Currey LM, Heupel MR, Simpfendorfer CA, Williams AJ (2014) Sedentary or mobile? Variability in space and depth use of an exploited coral reef fish. Mar Biol 161: 2155-2166

Davies CR (1996) Inter-reef movement of the common coral trout, Plectropomus leopardus. Great Barrier Reef Marine Park Authority Research Publication No. 61. GBRMPA, Townsville

> Donelson JM, Munday PL, McCormick MI, Nilsson GE (2011) Acclimation to predicted ocean warming through developmental plasticity in a tropical reef fish. Glob Change Biol 17:1712-1719

Dubin RE, Baker JD (1982) Two types of cover-seeking behavior at sunset by the princess parrotfish, Scarus taeniopterus, at Barbados, West Indies. Bull Mar Sci 32:572-583

Dulvy NK, Freckleton RP, Polunin NVC (2004) Coral reef cascades and the indirect effects of predator removal by exploitation. Ecol Lett 7:410-416

- Espinoza M, Farrugia TJ, Webber DM, Smith F, Lowe CG (2011) Testing a new acoustic telemetry technique to quantify long-term, fine-scale movements of aquatic animals. Fish Res 108:364-371

Ferreira BP (1995) Reproduction of the common coral trout Plectropomus leopardus (Serranidae: Epinephelinae) from the Central and Northern Great Barrier Reef, Australia. Bull Mar Sci 56:653-669

Fox J, Weisberg $\mathrm{S}$ (2011) An $\{\mathrm{R}\}$ companion to applied regression, 2nd edn. Sage, Thousand Oaks, CA. http:// socserv.socsci.mcmaster.ca/jfox/Books/Companion

> Frias-Torres S (2006) Habitat use of juvenile goliath grouper Epinephelus itajara on the Florida Keys, USA. Endang Species Res 2:1-6

Goeden GB (1978) A monograph of the coral trout Plectropomus leopardus. Queensland Fish Serv Res Bull 1:1-42

> Grandcourt EM (2002) Demographic characteristics of a selection of exploited reef fish from the Seychelles: preliminary study. Mar Freshw Res 53:123-130

Heupel MR, Webber DM (2012) Trends in acoustic tracking: Where are the fish going and how will we follow them? Am Fish Soc Symp 76: Advances in fish tagging and marketing technology, 24-28 February 2008, Auckland, p 219-231

> Heupel MR, Semmens JM, Hobday AJ (2006) Automated acoustic tracking of aquatic animals: scales, design and deployment of listening station arrays. Mar Freshw Res 57:1-13

Heupel MR, Simpfendorfer CA, Olsen EM, Moland E (2012) Consistent movement traits indicative of innate behavior in neonate sharks. J Exp Mar Biol Ecol 432-433:131-137

> Horne JS, Garton EO, Krone SM, Lewis JS (2007) Analyzing animal movements using Brownian bridges. Ecology 88: 2354-2363

> Hutchinson N, Rhodes KL (2010) Home range estimates for squaretail coralgrouper, Plectropomus areolatus (Rüppell 1830). Coral Reefs 29:511-519

James D, Hornik K (2013) chron: Chronological objects which can handle dates and times. R package v. 2.3-44

Jonsen ID, Myers RA, James MC (2007) Identifying leatherback turtle foraging behaviour from satellite telemetry using a switching state-space model. Mar Ecol Prog Ser 337:255-264

Kaunda-Arara B, Rose G (2004) Homing and site fidelity in the greasy grouper Epinephelus tauvina (Serranidae) within a marine protected area in coastal Kenya. Mar Ecol Prog Ser 277:245-251

Kiel BL (2004) Homing and spatial use of gag grouper Mycteroperca microlepis. PhD dissertation, University of Florida, Miami, FL

> Kingsford MJ (1992) Spatial and temporal variation in predation on reef fishes by coral trout (Plectropomus leopardus, Serranidae). Coral Reefs 11:193-198

Kingsford MJ (2009) Contrasting patterns of reef utilization and recruitment of coral trout (Plectropomus leopardus) and snapper (Lutjanus carponotatus) at One Tree Island, southern Great Barrier Reef. Coral Reefs 28:251-264 
Knip D, Heupel M, Simpfendorfer C, Tobin A, Moloney J (2011) Ontogenetic shifts in movement and habitat use of juvenile pigeye sharks Carcharhinus amboinensis in a tropical nearshore region. Mar Ecol Prog Ser 425: 233-246

Knip DM, Heupel MR, Simpfendorfer CA (2012) Habitat use and spatial segregation of adult spottail sharks Carcharhinus sorrah in tropical nearshore waters. J Fish Biol 80: 767-784

Little LR, Smith ADM, Mcdonald AD (2005) Effects of size and fragmentation of marine reserves and fisher infringement on the catch and biomass of coral trout, Plectropomus leopardus, on the Great Barrier Reef, Australia. Fish Manag Ecol 12:177-188

> Loseto LL, Richard P, Stern GA, Orr J, Ferguson SH (2006) Segregation of Beaufort Sea beluga whales during the open-water season. Can J Zool 84:1743-1751

- Mapstone BD, Little LR, Punt AE, Davies CR and others (2008) Management strategy evaluation for line fishing in the Great Barrier Reef: balancing conservation and multi-sector fishery objectives. Fish Res 94:315-329

McClanahan T, Mangi S (2000) Spillover of exploitable fishes from a marine park and its effect on the adjacent fishery. Ecol Appl 10:1792-1805

> Mclean DL, Harvey ES, Meeuwig JJ (2011) Declines in the abundance of coral trout (Plectropomus leopardus) in areas closed to fishing at the Houtman Abrolhos Islands, Western Australia. J Exp Mar Biol Ecol 406:71-78

Miller I, Cheal AJ, Emslie MJ, Logan M, Sweatman H (2012) Ongoing effects of no-take marine reserves on commercially exploited coral trout populations on the Great Barrier Reef. Mar Environ Res 79:167-170

> Monaco ME, Friedlander AM, Caldow C, Christensen JD and others (2007) Characterising reef fish populations and habitats within and outside the US Virgin Islands Coral Reef National Monument: a lesson in marine protected area design. Fish Manag Ecol 14:33-40

> Munday PL, Jones GP, Pratchett MS, Williams AJ (2008) Climate change and the future for coral reef fishes. Fish Fish 9:261-285

> Newton K, Côté IM, Pilling GM, Jennings S, Dulvy NK (2007) Current and future sustainability of island coral reef fisheries. Curr Biol 17:655-658

Nilsson GE, Crawley N, Lunde IG, Munday PL (2009) Elevated temperature reduces the respiratory scope of coral reef fishes. Glob Change Biol 15:1405-1412

Pastor J, Verdoit-Jarraya M, Astruch P, Dalias N, Nelva Pasqual JS, Saragoni G, Lenfant P (2009) Acoustic telemetry survey of the dusky grouper (Epinephelus marginatus) in the Marine Reserve of Cerbère-Banyuls: informations on the territoriality of this emblematic species. C R Biol 332:732-740

Payne N, Gillanders B, Webber D, Semmens J (2010) Interpreting diel activity patterns from acoustic telemetry: the need for controls. Mar Ecol Prog Ser 419:295-301

Pinheiro J, Bates D, DebRoy S, Sarkar D, R Development Core Team (2013) nlme: Linear and nonlinear mixed effects models. R package v. 3.1-109, http://CRAN.Rproject.org/package $=$ nlme

Powell RP (2000) Animal home ranges and territories and home range estimators. In: Boitani L, Fuller TK (eds) Research techniques in animal ecology: controversies and consequences. Columbia University Press, New York, NY, p 65-110

R Development Core Team (2013) R: A language and environment for statistical computing. R Foundation for Statistical Computing, Vienna. www.r-project.org

Roscoe DW, Hinch SG, Cooke SJ, Patterson DA (2010) Behaviour and thermal experience of adult sockeye salmon migrating through stratified lakes near spawning grounds: the roles of reproductive and energetic states. Ecol Freshw Fish 19:51-62

> Sadovy Y (2005) Trouble on the reef: the imperative for managing vulnerable and valuable fisheries. Fish Fish 6 : 167-185

Sadovy de Mitcheson Y, Colin PL (2012) Reef fish spawning aggregations: biology, research and management. In: Noakes D (ed) Fish \& fisheries series, Vol 35. Springer, Dordrecht

Samoilys MA (1987) Aspects of the behaviour, movements and population density of Plectropomus leopardus (Lacepede) (Pisces: Serranidae) at Heron Island reef, southern Great Barrier Reef, Australia. MSc thesis, University of Queensland, Brisbane

Samoilys MA (1997) Movement in a large predatory fish: coral trout, Plectropomus leopardus (Pisces: Serranidae), on Heron Reef, Australia. Coral Reefs 16:151-158

Samoilys MA (2000) Reproductive dynamics of an exploited serranid on the Great Barrier Reef. PhD dissertation, James Cook University, Townsville

Samoilys MA, Squire LC (1994) Preliminary observations on the spawning behaviour of coral trout, Plectropomus leopardus (Pisces: Serranidae), on the Great Barrier Reef. Bull Mar Sci 54:332-342

Schnute JT, Boers N, Haigh R, Grandin C, Johnson A, Wessel P, Antonio F (2013) PBSmapping: Mapping fisheries data and spatial analysis tools. R package v. 2.66.53. http: //CRAN.R-project.org/package=PBSmapping

Simpfendorfer CA, Heupel MR, Hueter RE (2002) Estimation of short-term centers of activity from an array of omnidirectional hydrophones and its use in studying animal movements. Can J Fish Aquat Sci 59:23-32

St. John J (2001) Temporal variation in the diet of a coral reef piscivore (Pisces: Serranidae) was not seasonal. Coral Reefs 20:163-170

Sumpton W, Mayer D, Brown I, Sawynok B, McLennan M, Butcher A, Kirkwood J (2008) Investigation of movement and factors influencing post-release survival of linecaught coral reef fish using recreational tag-recapture data. Fish Res 92:189-195

> Szedlmayer S (1997) Ultrasonic telemetry of red snapper, Lutjanus campechanus, at artificial reef sites in the northeast Gulf of Mexico. Copeia 1997:846-850

Thompson AA, Mapstone BD (2002) Intra- versus interannual variation in counts of reef fishes and interpretations of long-term monitoring studies. Mar Ecol Prog Ser 232:247-257

Tobin A, Schlaff A, Tobin R, Penny A and others (2010) Adapting to change: minimising uncertainty about the effects of rapidly-changing environmental conditions on the Queensland coral reef fin fish fishery. Final Report to the Fisheries Research \& Development Corporation, Project 2008/103. Fishing \& Fisheries Research Centre Technical Report no. 11, James Cook University, Townsville

Tobin A, Currey L, Simpfendorfer C (2013) Informing the vulnerability of species to spawning aggregation fishing using commercial catch data. Fish Res 143:47-56

Tulevech SM, Recksiek CW (1994) Acoustic tracking of adult white grunt, Haemulon plumieri, in Puerto Rico and Florida. Fish Res 19:301-319 
Warnes GR (2013) gmodels: Various R programming tools for model fitting. $\mathrm{R}$ package v. 2.15.4.1. http://CRAN. R-project.org/package $=$ gmodels

Winn HE, Bardach JE (1959) Differential food selection by moray eels and a possible role of the mucous envelope of parrot fishes in reduction of predation. Ecology 40: 296-298

Zeller DC (1997) Home range and activity patterns of the coral trout Plectropomus leopardus (Serranidae). Mar Ecol Prog Ser 154:65-77

Zeller DC (1998) Spawning aggregations: patterns of movement of the coral trout Plectropomus leopardus (Serra-

Editorial responsibility: Ivan Nagelkerken,

Adelaide, South Australia, Australia nidae) as determined by ultrasonic telemetry. Mar Ecol Prog Ser 162:253-263

Zeller DC (1999) Ultrasonic telemetry: its application to coral reef fisheries research. Fish Bull 97:1058-1065

Zeller DC (2002) Tidal current orientation of Plectropomus leopardus (Serranidae). Coral Reefs 21:183-187

Zeller DC, Russ GR (1998) Marine reserves: patterns of adult movement of the coral trout (Plectropomus leopardus (Serranidae)). Can J Fish Aquat Sci 55:917-924

Zeller D, Stoute SL, Russ GR (2003) Movements of reef fishes across marine reserve boundaries: effects of manipulating a density gradient. Mar Ecol Prog Ser 254:269-280

Submitted: April 7, 2014; Accepted: November 13, 2014 Proofs received from author(s): January 30, 2015 